\title{
ANÁLISE SWOT DE HEMEROTECAS: ACESSIBILIDADE E PRESERVAÇÃO DOCUMENTAL DO CENTRO DE CIÊNCIAS JURÍDICAS DA UNIVERSIDADE FEDERAL DE PERNAMBUCO
}

\author{
Newspaper clipping libraries SWOT analysis: accessibility \\ and document preservation at the Center of Legal \\ Sciences in the Federal University of Pernambuco
}

\section{Diego Andres Salcedo \\ salcedo.da@gmail.com \\ Doutor em Comunicação. Professor no Dep. de Ciência da Informação da UFPE. Coordenador do Grupo IMAGO.}

\author{
Paulo Vitor dos Santos Crispim \\ pv_crispim@hotmail.com \\ Graduando em Biblioteconomia na Universidade Federal \\ de Pernambuco Experiência no área de Técnico em se- \\ gurança do Trabalho no campo de Construção cívil; \\ Experiência em Hemeroteca e Livros Raros no campo da \\ Biblioteconomia.
}

\author{
Kézia de Lira Feitosa \\ kzlfeitosa@gmail.com \\ Graduanda em Biblioteconomia na Universidade \\ Federal de Pernambuco. Atualmente integra o Grupo \\ de CoPesquisa IMAGO, vinculado ao Departamento \\ de Ciência da Informação (DCI) e ao Programa de Pós- \\ Graduação em Ciência da Informação (PPGCl), ambos na \\ Universidade Federal de Pernambuco (UFPE).
}

\section{José Almeida Lins Neto}

josealmeidalinsneto@outlook.com

RESUMO: No presente artigo, buscou-se analisar os aspectos internos da Hemeroteca do Centro de Ciências Jurídicas da Universidade Federal de Pernambuco por meio de análise SWOT. Por meio do método exploratório e descritivo, a pesquisa possibilitou a identificação das forças, fraquezas, ameaças e oportunidades, assim como foi possível encontrar possíveis soluções para as principais problemáticas que envolvem a Hemeroteca. O estudo de caso revelou duas fraquezas consideradas de primeira ordem. A primeira diz respeito ao mau acondicionamento do acervo, que ocasionou grandes prejuízos e perdas à coleção de Jornais raros de Pernambuco datados do século XIX e XX. Tais perdas foram ocasionadas principalmente por ataque de agentes biológicos e físicos de deterioração, além das sujidades e estado precário do ambiente em que se encontravam. A segunda diz respeito a inefetividade da acessibilidade interna do edifício. A principal contribuição do 
estudo reside na solução desses problemas ao indicar os passos necessários para o acondicionamento adequado e proteção dos documentos contra os agentes de deterioração físicos, químicos e biológicos que podem atacar os periódicos da Hemeroteca, assim como indicar as possíveis soluções para a otimização do acesso à Hemeroteca para as pessoas com necessidades especiais.

PALAVRAS-CHAVE: SWOT. Hemeroteca. Agentes de Deterioração. Acessibilidade. Preservação Documental.

\begin{abstract}
This article analyzes the internal aspects of the Newspaper Clipping Library of the Center of Legal Sciences at the Federal University of Pernambuco through SWOT analysis. Through an exploratory and descriptive method the research made possible to identify the strengths, weaknesses, threats and opportunities, as well as possible solutions to the main problems that involve the unit. The case study revealed two weaknesses considered to be of the first order. The first one concerns the bad packaging of the collection, which caused considerable damages and losses to the collection of rare newspapers of Pernambuco dating from the 19th and 20th centuries. These losses were mainly caused by the attack of biological and physical agents of deterioration, besides the soils and precarious state of the environment in which they were. The second one concerns the ineffectiveness of the building's internal accessibility. The main contribution of the study is to solve these problems by indicating the necessary steps for the adequate document packaging and protection against the physical, chemical and biological deterioration agents that can attack the journals of the Library, as well as to indicate the possible solutions for the optimization of the access to the Library for people with special needs.
\end{abstract}

KEYWORDS: SWOT. Newspaper Clipping Library. Deteriorating Agents. Accessibility. Document Preservation.

\title{
1 Introdução
}

Uma unidade informacional é caracterizada por ser uma entidade que trata, coleta, organiza e disponibiliza para os usuários as informações em potencial existentes em seu acervo. O desenvolvimento da análise interna de uma unidade implica diretamente na otimização dos serviços prestados aos usuários. Este trabalho possibilita uma melhor compreensão dos problemas, servindo de base à possibilidade de tornar o ambiente um espaço positivamente potencializado para seu público.

A pesquisa que trata este artigo fez uma análise do ambiente interno da Hemeroteca vinculada à Biblioteca do Centro de Ciências Jurídicas da Universidade Federal de Pernambuco-CCJ, uma unidade de informação singular que possui interessantes particularidades. A pesquisa buscou apresentar os dados obtidos por meio da análise 
SWOT, feita na Hemeroteca do CCJ, com enfoque nos problemas considerados de primeira ordem.

Para alcançar esse objetivo, foram realizadas quatro ações específicas, a saber: i) revisão dos conceitos de gestão, planejamento estratégico e análise SWOT na literatura científica nas áreas de Ciência da Informação e Administração; ii) visita à unidade informacional para entrevista com a gestora; iii) análise dos pontos fortes e fracos da organização e as oportunidades e ameaças às quais ela está exposta; e iv) formulação da análise SWOT.

As metodologias utilizadas, conforme o objetivo do estudo, foram a exploratória e a descritiva. Desde a perspectiva dos procedimentos a pesquisa foi bibliográfica e documental em conformidade com a indicação de Gil (2007). Assim, a revisão da literatura especializada foi feita, principalmente, em livros e artigos científicos. Para recuperar essa literatura foi utilizada a Base de Dados Referenciais de Artigos de Periódicos em Ciência da Informação-BRAPCI e a base de revistas científicas brasileira ScientificElectronic Library Online -SciELO.

A Hemeroteca do CCJ, localizada na cidade do Recife, Estado de Pernambuco, foi o estudo de caso da pesquisa. Uma visita técnica proporcionou o contato direto com o ambiente e também com a gestora, possibilitando o embasamento para construção da análise SWOT. Também foi feito um estudo aprofundado sobre quais são as características de uma hemeroteca e sua relação com os potenciais serviços de informação e a demanda por um planejamento estratégico.

\section{A hemeroteca}

O termo hemeroteca refere-se à uma coleção de revista ou jornais. Origina-se do grego heméra que significa "dia”, e théke que significa "depósito" ou "caixa" (BUONOCORE, 1976, p. 243).

Conforme Oliveira (2005, p.8), a função da hemeroteca "se destina à conservação das informações publicadas periodicamente sobre um determinado assunto, possibilitando assim, o resgate e acesso ao produto informacional que foi disponibilizado anos atrás". Ou seja, uma hemeroteca conserva a história de um determinado período e é uma grande fonte de pesquisa para resgate da memória de um determinado local, instituição ou população. 
Neste sentido "é relevante que toda e qualquer ferramenta disponível seja utilizada para contribuir, cada qual à sua forma, para o desenvolvimento de modelos de divulgação da memória social" (SALCEDO, 2008, p. 169).Sob essa perspectiva, as hemerotecas estão inseridas em um espaço informacional que ajuda a tangenciar a prática de conhecimento, isso pelo fato de se comportarem como bases de pesquisas, pilares teóricos das condições sócio-históricas e fontes informativas. (AZEVEDO NETTO, 2017, p. 79).

Sob uma perspectiva histórica, em 1965, a Universidade recebeu o nome de Universidade Federal de Pernambuco (UFPE) e a Faculdade de Direito do Recife (FDR) passou a constituir o Centro de Ciências Jurídicas (CCJ), única unidade acadêmica instalada fora do campus universitário. A FDR, desde os seus primeiros anos de fundação, atuava não apenas como centro de formação de bacharéis, mas, sobretudo, como um espaço intelectual, poético, crítico, filosófico, sociológico, artístico e jurídico. De lá, surgiram grandes discussões e polêmicas que empolgavam a sociedade da época.

Até hoje, a FDR é palco para inúmeras manifestações e ações do corpo discente.

$$
\begin{aligned}
& \text { A grandeza intelectual e moral da Faculdade, que tem crescido sem- } \\
& \text { pre no lento correr dos tempos, está sobretudo no seu feitio humanista. } \\
& \text { Tornou em toda a sua vida, mais a feição de universidade, com a visão } \\
& \text { globalizante e transformadora do seu meio, do que a atitude formalis- } \\
& \text { ta de uma redução ao formalismo da prática forense. Nisto constituiu } \\
& \text { a sua grandeza. Formou, sem dúvida, famosos praxistas e advogados, } \\
& \text { mas foi imenso o número de jurisconsultos, filósofos, poetas, economis- } \\
& \text { tas, sociólogos, ensaístas, políticos e estadistas, agitadores de idéias que } \\
& \text { abalaram a sociedade, no aceleramento do progresso e no bloqueio ou } \\
& \text { desceleramento da rotina. (FERREIRA, 1977, p. 6). }
\end{aligned}
$$

Em consequência das constantes mudanças da FDR, o arquivo e a biblioteca sofreram grandes perdas em seu acervo. Outrossim, constantes trabalhos têm sido realizados para preservar e conservar o acervo criando as condições para que o seu arquivo e asua biblioteca possam ser caracterizados e reconhecidos como lugares de memória no sentido sugerido por Murguia (2010). O autor enuncia que "toda memória, oficial ou não, precisa de um enquadramento, de uma organização para que possa vir a ser um elemento importante na formação das identidades"(2010, p. 8).

A Hemeroteca do CCJ está vinculada à Faculdade de Direito do Recife, que por sua vez está ligada à Universidade Federal de Pernambuco e seu acervo possui periódicos nacionais e internacionais, publicados nos séculos XIX, XX e XXI. Uma parte do acervo da hemeroteca foi contemplado com um projeto de conservação de 
memória intitulado "Resgate documental dos jornais raros da Faculdade de Direito do Recife", criado em 2009, em parceria com a Fundação Joaquim Nabuco, órgão vinculado ao Ministério da Educação.

\begin{abstract}
A denominação Faculdade de Direito do Recife permanece apenas por questões históricas, já que hoje constitui o CCJ/UFPE com três departamentos: Departamento de Direito Público Geral e Processual, Departamento de Direito Público Especializado e Departamento de Teoria Geral do Direito e Direito Privado.Atualmente, a Faculdade compõe-se de um edifício sede, localizado na Praça Adolfo Cirne, e de dois (2) anexos, localizado na Rua do Hospício, onde funcionam os cursos de Mestrado, de Doutorado e de Especialização, bem como o Núcleo de Prática Jurídica, o Arquivo e a Hemeroteca (OLIVEIRA; PEREIRA, 2016, p.606).
\end{abstract}

Em novembro de 2009 foi realizada uma exposição no Espaço Memória da Faculdade, onde foram exibidos alguns volumes raros deste projeto. A primeira fase do processo durou seis meses e contou com atividades de desinfestação, higienização e acondicionamento dos jornais (ver figura 1).

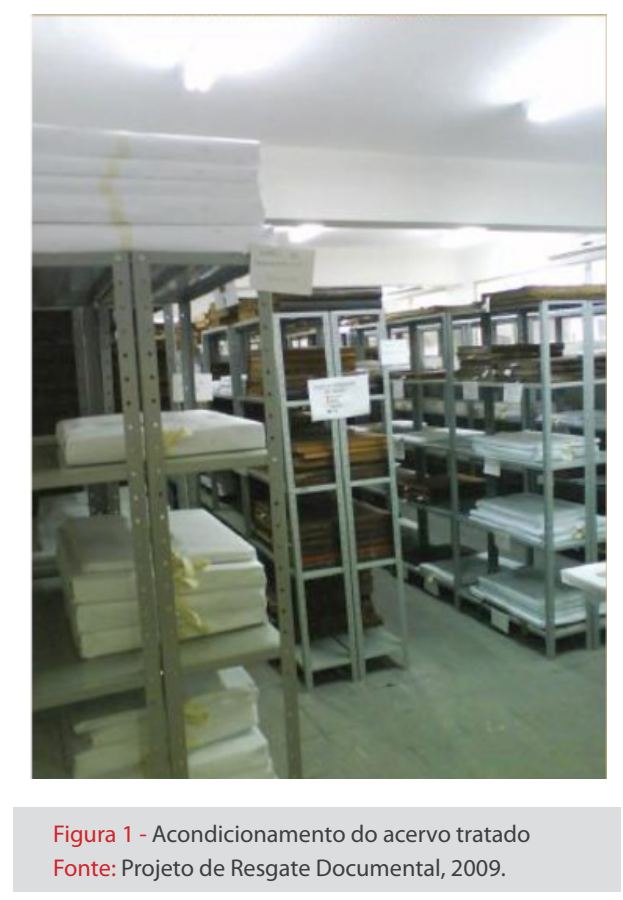

Essa coleção foi identificada por meio de banco de dados que contém fichas técnicas e fotos dos jornais. Os originais ficaram acondicionados em salas na hemeroteca, com 2.561 volumes, em 98 estantes, num ambiente climatizado, o que é essencial para a preservação desse acervo.

Durante a identificação dos documentos no acervo foram encontrados: certi- 
dões de idade, livros de matrícula, dossiês de aluno, registros de cartas de bacharéis e doutores, correspondências diversas, regimentos internos, boletins oficiais e provas. Todos esses documentos contêm a exomemória relativa a, por exemplo, educação brasileira dos períodos monárquicos e republicano, bem como indica características das relações socioculturais e político-econômicas.

Em agosto de 2014, a hemeroteca foi reinaugurada com novas e maisadequadas instalações. $\mathrm{O}$ acesso à coleção é restrito a fim de preservar as fontes primárias; para visitação, deve-se preencher o formulário de solicitação de pesquisa da coleção.O espaço físico do arquivo tem $140 \mathrm{~m}^{2}$ e está dividido em uma sala reservada à administração, um laboratório, um espaço para pesquisador e um salão amplo, onde ficam os arquivos deslizantes e o acervo tratado. O ambiente é climatizado e dispõe de controle de luminosidade.

\section{$3 \quad$ Planejamento estratégico e análise SWOT}

O Planejamento Estratégico é um processo gerencial que se refere à formulação de objetivos para a elaboração e execução de ações, levando em conta as condições internas e externas à empresa e sua evolução esperada. O planejamento estratégico é, principalmente, relacionado com o ajustamento da organização ao seu ambiente, resolvendo problemas básicos, contornando as limitações, capitalizando sobre vantagens herdadas ou desenvolvidas e aproveitando as principais oportunidades (BOWER, 1966).

Oliveira (1998, p.46) argumenta que "o planejamento estratégico é um processo gerencial que possibilita ao executivo estabelecer o rumo a ser seguido pela empresa, com vistas a obter um nível de otimização na relação da empresa com o ambiente." Neste sentido, o planejamento estratégico completo requer muito mais esforço e dedicação do que normalmente se imagina, mas se feito com qualidade formará o caminho para alcançar as metas da unidade.

As instituições que colocam seus planos e práticas com eficiência e eficácia são as que abandonam as estratégias errôneas com facilidade e traçam novos rumos, aproveitando boas oportunidades, formando bons líderes e criando resultados lucrativos e sustentáveis.Nesse sentido, uma análise SWOT é uma ferramenta utilizada, sob a perspectiva da administração, para fazer a análise do ambiente interno e serve 
como informação de tomada de decisão gerencial, bem como auxilia no planejamento estratégico em uma instituição.

Caracterizada pela sua simplicidade de elaboração, pode ser utilizada para qualquer tipo de análise de situação. A técnica de análise SWOT foi elaborada pelo norte-americano Albert Humphrey, durante o desenvolvimento de um projeto de pesquisa na Universidade de Stanford entre as décadas de 1960 e 1970. O termo SWOT diz respeito à sigla das palavras Strenghts(forças), Weaknesses (fraquezas), Opportunities (oportunidades) e Threats (ameaças), que significam, respectivamente, forças, fraquezas, oportunidades e ameaças.

Essas quatro dimensões possuem particularidades distintas, a saber:

a) As forças são asvantagens internas da empresa em relação às concorrentes, como, por exemplo, a qualidade do produto oferecido e o bom serviço prestado ao cliente;

b) As fraquezas são as desvantagens internas da empresa em relação às concorrentes. Alguns exemplos são os altos custos de produção, má imagem, instalações inadequadas etc;

c) As oportunidades são aspectos externos positivos que podem potencializar a vantagem competitiva da empresa, assim como: mudanças nos gostos dos clientes, falência de empresa concorrente etc; e

d) As ameaças são aspectos externos negativos que podem pôr em risco a vantagem competitiva da empresa. Ex.: novos competidores, perda de trabalhadores fundamentais, etc.

É salutar direcionar atenção às situações que podem ser interpretadas, simultaneamente, tanto como oportunidade quanto como ameaça. Por exemplo, o crescimento de um setor de uma unidade informacional pode significar a oportunidade de aumento de produtividade, mas também pode ser interpretada como ameaça por requerer maiores desdobramentos no que tange à mão-de-obra disponível.É essencial ser objetivo e franco ao elaborar a análise. Deve-se desprender um olhar imparcial de modo que a realidade seja descrita e não as expectativas ou vontades de quem faz o planejamento.

A aplicação da análise SWOT na Hemeroteca trouxe à tona os grandes problemas que a unidade enfrenta e também as vantagens internas e externas com as 
quais a empresa pode contar. Os dados obtidos na análise podem ser observados no quadro a seguir:

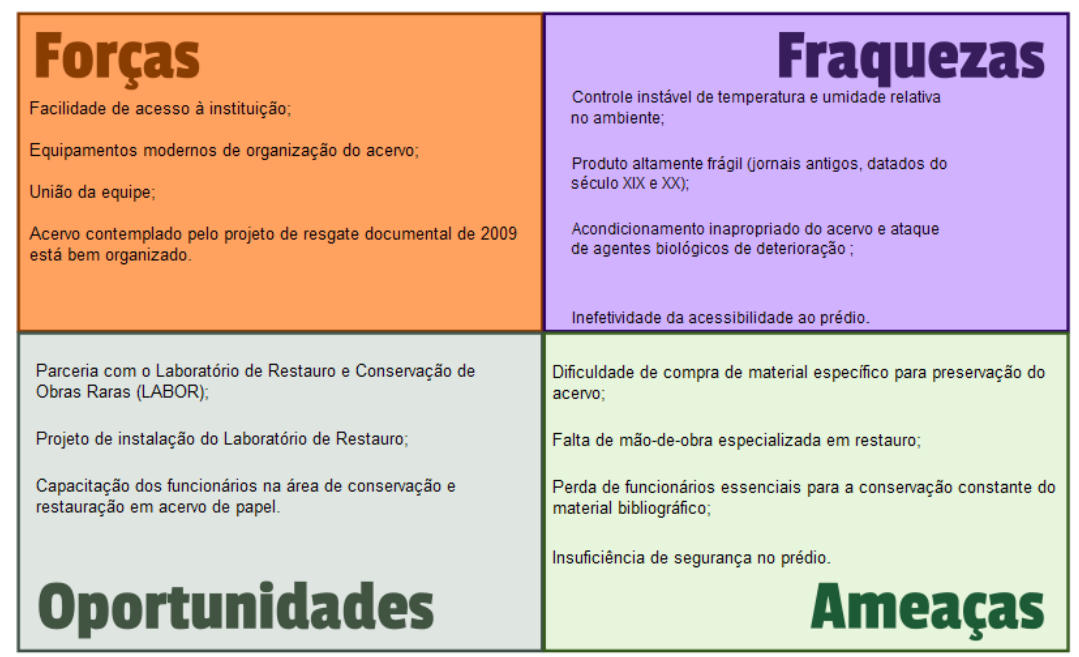

Quadro 1- Análise SWOT da Hemeroteca do CCJ da UFPE Fonte: os autores (2017)

Após o levantamento de dados, o foco do estudo foi voltado para os problemas considerados de primeira ordem, os que tratam da inefetividade da acessibilidade ao prédio da Hemeroteca e do estado muito precário de conservação de jornais raros, acondicionados no depósito da Hemeroteca do CCJ, e que não foram contemplados no projeto de resgate documental de 2009 (figura 2).

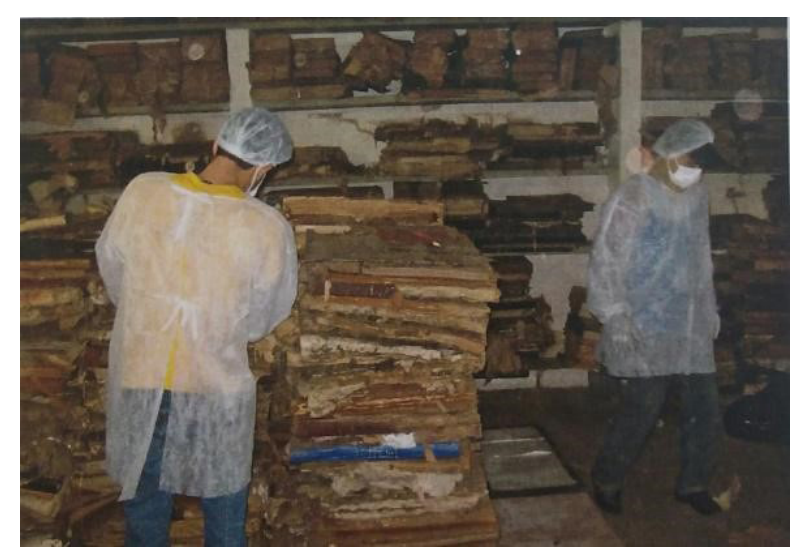

Figura 2 - Mau acondicionamento do acervo. Fonte: Projeto de Resgate Documental, 2009.

Esta situação implica em alto risco de perda do acervo por agentes de deterioração assim como a perda da memória jornalística jurídica de Pernambuco, levando em consideração a peculiaridade do acervo que contém informações de alta relevância 
sobre o estado de Pernambuco.

\section{Preservação, conservação e restauro}

A partir dos indicadores da análise SWOT feita na Hemeroteca foi possível perceber que grande parte dos problemas encontrados diz respeito ao mau acondicionamento do acervo. De modo geral, é necessário um melhor estudo e adequação no que tange à preservação e à conservação dos materiais do acervo. Para preservar, conservar e restaurar um acervo bibliográfico, temos que, previamente, conhecer a natureza dos materiais que formam os documentos do acervo da unidade de informação e como eles se comportam diante dos agentes de deterioração aos quais serão expostos.

É de grande importância que saibamos distinguir as principais diferenças entre estes conceitos, tão próximos e distintos entre si, para que as intervenções a serem feitas no acervo sejam eficientes e eficazes. Enquanto o termo preservação refere-se a todas as ações, pré e pós-danos que protejam e resguardem a integridade do documento, corroborando com as diretrizes do Manual Técnico de Preservação e Restauração da Biblioteca Nacional (2011, p.4), que definem o termo como "toda a ação que se destina à salvaguarda dos registros documentais" incluindo tanto o restauro quanto a conservação, a conservação somente diz respeito aos cuidados prévios que evitem uma futura intervenção.

Teijeler (2007 p.47) aponta a existência de dois tipos de conservação. A Conservação Preventiva, que contribui diretamente ou indiretamente para a conservação e integridade dos acervos, criando estratégias administrativas, políticas e procedimentos padrões para prevenir ou retardar a degradação. A Conservação Reparadora, que é toda a intervenção na estrutura dos materiais que compõem o documento, visando à melhoraria do seu estado físico.

Para Cessares (2000, p.12) a definição de restauração é: "um conjunto de medidas que objetivam a estabilização ou a reversão de danos físicos ou químicos adquiridos pelo documento ao longo do tempo e do uso, intervindo de modo a não comprometer sua integridade e seu caráter histórico". Se houver uma boa conservação e acondicionamento dos documentos, futuramente não será necessária a intervenção do restauro nos jornais.

O acervo da hemeroteca do CCJ da UFPE é composto por periódicos raros 
do Séc. XIX e o suporte dos documentos que compõem o acervo é o papel jornal (ver figura 3). A definição desse suporte pelo Manual Técnico de Preservação e Restauração da Biblioteca Nacional diz que o papel jornal é destinado à produção de jornal e tem em sua composição a base de madeira desfibrada mecanicamente e branqueada. Isso faz com que esse tipo de papel possua uma grande quantidade de lignina, por isso tende a ficar ácido, amarelado e quebradiço com o passar do tempo.

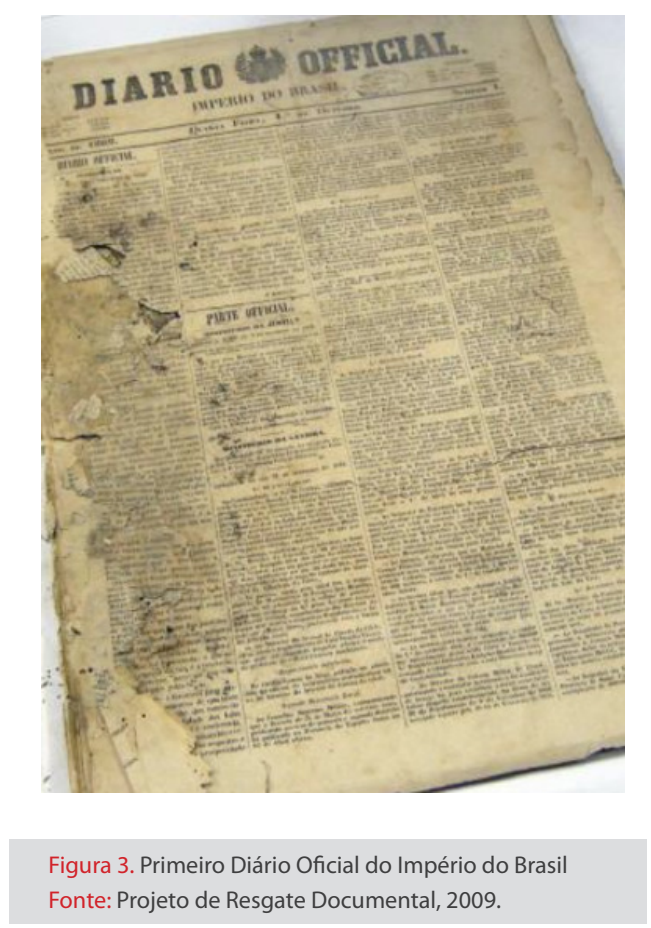

Por ser um suporte sensível, feito para ser "descartado", é necessário que se tenha conhecimento dos agentes de deterioração que podem causar danos ao acervo e ter cuidados no seu acondicionamento. $\mathrm{O}$ acondicionamento adequado objetiva a proteção dos documentos contra os agentes de deterioração físicos, químicos e biológicos que podem atacar os periódicos da hemeroteca (figura 4).

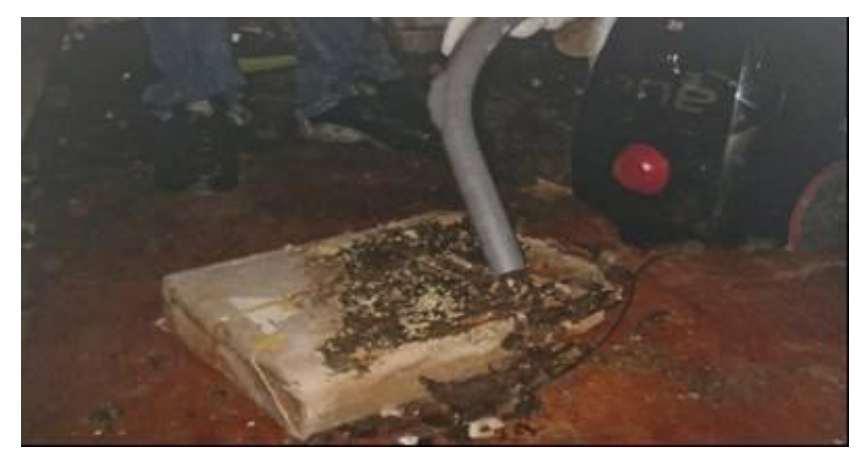

Figura 4 - Suporte atacado por agentes de deterioração Fonte: Projeto de Resgate Documental, 2009. 
Existe uma grande lista de agentes de deterioração que atingem o papel, são eles: fotodeterioração (deterioração pelo excesso de luz), sujidades (partículas de outros materiais), poeiras, amarelecimento, descoloração, teor ácido em sua própria essência e a biodeterioração. A biodeterioração é a deterioração e deformação causadas por agentes biológicos (fungos, bactérias, insetos, roedores) ao acervo. Visivelmente, esse é o agente que está trazendo maiores problemas na conservação e preservação do acervo da hemeroteca do CCJ. Isso acontece porque esses agentes se alimentam dos componentes formadores do papel, como celulose, açúcares e glicose. Se a temperatura e a umidade relativa nesse ambiente não estiverem regulares podem propiciar o desenvolvimento e a reprodução desses agentes gerando danos irreparáveis ao acervo. Sendo, então, o controle dos parâmetros de temperatura e umidade relativa (U.R) do ambiente onde os jornais são acondicionados uma das primeiras soluções possíveis.

Na conservação do papel, que é um suporte classificado como sensível, devemos levar em consideração as várias possibilidades de danos ao acervo. Os fatores ambientais, como a temperatura e a U.R., são elementos que devem estar em constante observação, pois a variação deles pode ocasionar danos gravíssimos ao longo do tempo, causando manchas e quebra do papel. Os níveis recomendados para o acondicionamento adequado do papel giram em torno de $20^{\circ} \mathrm{C}$ de temperatura e a umidade relativa entre $45 \%$ e $50 \%$.

Radiação de luz também é um agente de deterioração, provocando danos através da oxidação. Com isso, o papel se torna frágil, quebradiço, escurecido, as tintas desbotam ou mudam de cor, alterando a legibilidade dos documentos textuais e das encadernações. É importante evitar a luz natural e as lâmpadas fluorescentes, que são fontes geradoras de UV.

Para o monitoramento da temperatura e U.R. pode-se utilizar equipamentos de medição pontual ou contínua possibilitando o controle ativo do ambiente por meio de psicômetros, termômetros, Datalogger, desumidificadores, umificadores e condicionadores de ar e sistemas de climatização, por exemplo. Também é possível ter o controle passivo desses agentes através de medidas alternativas e diárias como, por exemplo: limitar o número de pessoas no espaço, evitar colocar material próximo a focos de luz e colocar persianas nas janelas a fim de evitar o contato direto com a luz solar.

Outros agentes de deterioração são os biológicos, insetos, roedores, fungos e 
até mesmo os seres humanos. A presença dos demais depende quase que exclusivamente das condições ambientais dominantes nas dependências onde se encontram os documentos. Assim, o controle dos agentes físicos (luz, temperatura e U.R) junto com a higienização regular do ambiente são fundamentais para a prevenção e solução destes problemas.

\section{$5 \quad$ A questão da acessibilidade}

Cada vez mais as pessoas portadoras de deficiência e com necessidades especiais defendem seu espaço e reivindicam seus direitos. Diante dessas demandas, instituições dos mais variados segmentos devem unir esforços para atender a essas necessidades visto que a questão da inclusão desta parte da sociedade, além de ser uma questão moral e de condição básica humana, é também regulamentada e orientada por diretrizes.

Diante do caráter social inerente à natureza das unidades informacionais, sejam bibliotecas, arquivos, hemerotecas ou afins, esse esforço deve existir, especialmente no que tange à popularização do acesso à informação, evitando, assim, que estas pessoas sejam incluídas em mais uma minoria social.

Nesta perspectiva, a missão maior é homogeneizar os serviços uma vez que, do ponto de vista da prestação de serviço e do tratamento com o público, as singularidades de todos os usuários devem ser levadas em consideração. Nesse sentido, a identificação do momento de interseção entre sistema e usuário deve ser visto como uma busca pelo pleno atendimento às especificidades.

Vale ainda citar que a execução de ações de inclusão deveriam ser pensadas no sentido de vantagem competitiva frente ao mercado, visto que ao se preocupar com estas questões a instituição ganha um olhar positivo por parte dos usuários e das pessoas envolvidas em atividades da mesma natureza.

De acordo com a Lei de Acessibilidade ${ }^{\circ}$ 5296, de 2 de dezembro de 2004, e a Lei Brasileira de Inclusão da Pessoa com Deficiência n 13.146, de 6 de julho de 2015, há uma série de regulamentos que priorizam o atendimento às pessoas portadoras de deficiência ou com mobilidade reduzida de forma que explicitam as normas gerais e critérios básicos para a promoção da acessibilidade.

De modo geral, o conceito de acessibilidade diz respeito às condições básicas 
para utilização, com segurança e autonomia, de edifícios públicos e privados, bem como seus espaços, mobília e equipamentos, possibilitando a maior independência possível quanto ao seu uso, de forma que as pessoas deficientes ou àqueles com dificuldade de locomoção possam usufruir do seu direito de ir e vir a todos os lugares que desejar.

De fato, a implantação da acessibilidade ainda é um grande desafio, tendo em vista as várias especificidades de cada tipo de deficiência, pois, para além das barreiras físicas presentes, existem as barreiras sociais e psicológicas que são inerentes às questões da pessoa com deficiência e que precisam ser combatidas: o preconceito, a ignorância e o medo.

Contudo, na perspectiva da acessibilidade em unidades de informação, de modo geral, podemos considerar o que MIGLIOLI e SANTOS (2017, p. 137) pontuaram acerca das bibliotecas, especificamente, indicando que existe certa tendência em priorizar serviços para deficientes visuais e/ou físicos. Segundo as autoras pensa-se primeiramente "em mudanças no espaço físico, melhorias na sinalização, adaptação de recursos maquínicos, a exemplo das categorias da avaliação das bibliotecas de curso superior pelo Ministério da Educação”.

A partir da visita técnica feita à Instituição foi possível observar que as medidas tomadas para garantir a acessibilidade para as pessoas com os diferentes tipos de deficiência no ambiente da Hemeroteca não funcionam de maneira efetiva. O prédio da hemeroteca do CCJ (ver figura 5) foi também a primeira reitoria da Universidade Federal de Pernambuco e a casa do primeiro reitor, Joaquim Amazonas. Trata-se de um prédio público, antigo, que traz consigo todas as suas limitações em relação à infraestrutura e possíveis intervenções. Sob um olhar mais amplo é possível dizer que, de certo modo, existe uma tentativa de adequação às necessidades especiais.

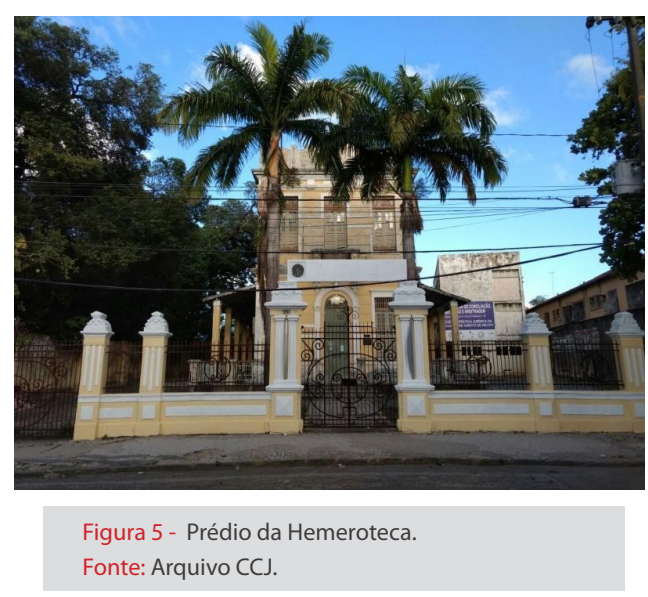


As portas de acesso e corredores do prédio são largas e existe uma rampa de acesso na entrada, o que facilita a locomoção. Todavia, a área de circulação e algumas seções da unidade informacional possuem degraus, o que inviabiliza a entrada de pessoas com mobilidade reduzida. Atualmente, a parte superior do prédio não está ativa, de forma que suas atividades são feitas no térreo. Caso seja necessário o uso das instalações do primeiro andar, esse fluxo também terá um caráter restritivo visto que o elevador existente no prédio não está funcionando. Além disso, é inexistente a sinalização tátil para deficientes visuais no chão, degraus e corrimão.

Diante de todas as limitações visualizadas no edifício e tendo em vista que a solução de todos os problemas levantados requer planejamento e investimento a longo prazo, é salutar sugerir a elaboração de uma política interna que leve em consideração a acessibilidade em todos os ambientes e serviços, de forma que existam materiais e equipamentos adequados e apoio técnico profissional, de acordo com as especificidades de cada pessoa com deficiência, conforme indica a Lei Brasileira de Inclusão da Pessoa com Deficiência.

A própria Lei indica no seu artigo 57, especificamente, que as edificações públicas e privadas de uso coletivo, que existem nos dias atuais, devem garantir acessibilidade à pessoa com deficiência em todas as suas dependências e serviços, tendo como referência as normas de acessibilidade vigentes. Ou seja, deve haver uma readequação de todo o ambiente.

\section{Considerações finais}

O planejamento de estratégias elaborado na pesquisa e sugerido neste artigo foi norteado com o objetivo de analisar os aspectos internos da Hemeroteca do Centro de Ciências Jurídicas da Universidade Federal de Pernambuco por meio de análise SWOT. Com isso, foi possível identificar os pontos fortes e fracos desse ambiente, além de sugerir meios para tentar neutralizar os pontos fracos e as ameaças e, ainda, indicar ações e metas a serem alcançadas na busca por uma gestão eficaz com a realização de um planejamento estratégico.

Os principais pontos fracos encontrados estão relacionados à conservação e à preservação dos materiais, além da falta de acessibilidade efetiva do prédio, o que, de fato, merecem uma ação mais enérgica para que sejam resolvidos. Existem diversas 
considerações e debates que precisam ser feitos a fim de que as unidades informacionais possam estar de acordo com as reivindicações de igualdade de oportunidades para as minorias sociais.

A importância desta discussão e a inserção de diretrizes desta natureza nas políticas destas unidades não podem ser subestimadas. A sensibilidade e empatia com as necessidades especiais significa que essas melhorias justificam um investimento de recursos.Além disso, a análise também nos aponta que, apesar das dificuldades enfrentadas, há diversas oportunidades que podem ser aproveitadas, como parcerias e capacitação dos funcionários. A análise do ambiente (interno e externo), bem como os estudos de usuários, permitirá identificar e planejar as necessidades da unidade de informação, o que garantirá uma vantagem competitiva frente aos concorrentes.

\section{Referências}

BOWER, Marvin. The willtomanage. New York: McGraw-Hill, 1966.

BUONOCORE, Domingo. Diccionario de Bibliotecologia. 2.ed. Buenos Aires: EdicionesMarymar, 1976.

BRASIL. DECRETO No 5.296 DE 2 DE DEZEMBRO DE 2004. Disponível em: <https://goo.gl/XA4qTg>. Acesso em: 25 maio 2017.

BRASIL. LEI No 13.146 de 6 de julho de 2015. Disponível em: <https://goo.gl/XA4qTg>. Acesso em: 25 maio 2017. CESSARES, Norma C. Como fazer prevenção preventiva em arquivos e bibliotecas. São Paulo: Arquivo do Estado e Imprensa Oficial, 2000.

FERREIRA, Pinto. A Faculdade de Direito e a Escola do Recife. Rev. Inf. Legisl., Brasília. ano 14, n. 55, jul./set. 1977. Disponível em: <https://goo.gl/ZudDsG>. Acesso em: 02 maio 2017.

GIL, A. C. Como elaborar projetos de pesquisa. 4.ed. São Paulo: Atlas, 2007.

MIGLIOLI, S.; SANTOS, G. A. Acessibilidade e serviços inclusivos para minorias sociais: a biblioteca do instituto nacional de educação de surdos. Revista ACB: Biblioteconomia em Santa Catarina, v. 22, n. 1, 2017. Disponível em: <http://www.brapci.ufpr.br/brapci/v/a/23031>. Acesso em: 22 jun. 2017.

MURGUIA, Eduardo Ismael (Org.). Memória: um lugar de diálogo para arquivos, bibliotecas e museus. São Carlos, SP: Compacta Gráfica e Editora, 2010.

NETTO, C.X. Azevedo et al. A hemeroteca enquanto espaço documental, informacional e memorial. Em Questão, v. 20, n. 2, Disponível em: <http://www.brapci.ufpr.br/brapci/v/a/16138>. Acesso em: 21 jun. 2017.

OLIVEIRA, Danielle Alves de.; PEREIRA, Ingrid Rique da Escossia. Arquivo da Faculdade de Direito do Recife: preservando a memória acadêmica. Revista Analisando em Ciência da Informação - RACIn, João Pessoa, v. 4, n. especial, p. 603-613, out. 2016. Disponível em: <https://goo.gl/3WpuFx>.

OLIVEIRA, Djalma. Planejamento Estratégico: conceitos, metodologia, práticas. 12.ed. São Paulo: Editora Atlas $\mathrm{S} / \mathrm{A}, 1998$. 
OLIVEIRA, Juliana Buse de; MEDEIROS, Rildeci. Hemeroteca sobre saques e invasões: do impresso ao digital. 2005. Disponível em: <https://goo.gl/vwcwqF>. Acesso em: 15 jun. 2016.

SALCEDO, Diego Andres. Filatelia e memória: pequenos embaixadores de papel. In: VERRI, Gilda M. W. (Org.). Registros do passado no presente. Recife: Bagaço, 2008. p. 155-195.

SPINELLI, Jayme; BRANDÃO, Emiliana; FRANÇA, Camila. Manual técnico de preservação e conservação documento extrajudiciais CNJ. Rio de Janeiro: Biblioteca Nacional, 2011.

TEIJGELER, René. Conservação preventiva da herança documental em climas tropicais: uma bibliografia anotada. Lisboa: Biblioteca Nacional, 2007. 